\title{
The form, distribution and mobility of arsenic in soils contaminated by arsenic trioxide, at sites in southeast USA
}

\author{
Li Yang, and Rona J. Donahoe
}

\begin{abstract}
Soils from many industrial sites in southeastern USA are contaminated with As because of the application of herbicide containing As2O3. Among those contaminated sites, two industrial sites, FW and $\mathrm{BH}$, which are currently active and of most serious environmental concerns, were selected to characterize the occurrence of As in the contaminated soils and to evaluate its environmental leachability. The soils are both sandy loams with varying mineralogical and organic matter contents. Microwave-assisted acid digestion (EPA method 3051) of the contaminated soils indicated As levels of up to $325 \mathrm{mg} / \mathrm{kg}$ and $900 \mathrm{mg} / \mathrm{kg}$ (dry weight basis) for FW and BH soils, respectively. However, bulk X-ray powder diffraction (XRD) analysis failed to find any detectable As-bearing phases in either of the studied soil samples. Most of the soil As was observed by scanning electron microscopy, coupled with energy dispersive X-ray spectroscopy (SEM/EDX), to be disseminated on the surfaces of fine-grained soil particles in close association with $\mathrm{Al}$ and $\mathrm{Fe}$. A few As-bearing particles were detected in $\mathrm{BH}$ soil using electron microprobe analysis (EMPA). Synchrotron micro-XRD and X-ray absorption near-edge structure (XANES) analyses indicated that these As-rich particles were possibly phaunouxite, a mineral similar to calcium arsenate, which could have been formed by natural weathering after the application of As2O3. However, the scarcity of those particles eliminated them from playing any important role in As sequestration.

Synthetic acid rain sequential batch leaching experiments showed distinct As leaching behaviors of the two studied soil samples: BH soil, which has the higher As content, showed a slow, steady release of As, while FW soil, with a lower As content, showed a much quicker release and lower overall retention of As upon leaching. Sequential chemical extraction experiments were carried out using a simplified 4-step sequential chemical extraction procedure (SCEP) previously developed to characterize the fractionation of As and better understand the different leaching behaviors of the two studied soils. It was shown that only about $50 \%$ of the total extractable As was removed by the first two extraction steps, which represented the most weakly bonded and readily available As for environmental leaching. Compared with the sequential leaching experiments, it was further indicated that only half of the As associated with phases extracted by the second SCEP step was mobilized by SPLP leaching. Although microwave-assisted acid digestion results showed similar $\mathrm{Al}$ and $\mathrm{Fe}$ contents in both soils, the sequential chemical extraction experiments indicated that $\mathrm{BH}$ soil has a much higher content of amorphous $\mathrm{Al}$ and $\mathrm{Fe}$ phases and that a comparably higher portion of soil As was associated with those materials. The experimental results suggest that remediation efforts for the contaminated sites can be directed towards enhancing the formation of more stable As-bearing compounds in the soils to reduce the environmental leachability of As.
\end{abstract}




\section{Introduction}

Arsenic and its compounds are ubiquitous in nature. It ranks twentieth among the elements in abundance in the Earth's crust and is a major constituent of more than 200 mineral species (National Research Council, 1977). The average concentration of As in crustal rocks is 2-3 $\mathrm{mg} / \mathrm{kg}$, with the highest concentrations occuring primarily in association with sulfide deposits, such as arsenopyrite and pyrite (Backer and Chesnin, 1975). Arsenic is present in all types of soil, with its exact concentration varying among geographic regions as determined by the geologic history of the area (Colbourn et al., 1975). Background concentrations of As in US soils range from less than $1 \mathrm{mg} / \mathrm{kg}$ to $97 \mathrm{mg} / \mathrm{kg}$, with an average of about $5-7 \mathrm{mg} / \mathrm{kg}$ (Shacklette and Boerngen, 1984 and Dragun and Chiasson, 1991).

Despite its universal presence, the occurrence of As in drinking water poses a threat to human health, even at relatively low concentrations (ATSDR, 2000). Chronic ingestion of As-enriched drinking water can lead to a series of diseases, including skin tumors, liver dysfunction, gangrene and hearing loss (Hutton, 1987). After further study of its carcinogenic risk, the US EPA has lowered the current maximum contaminant level (MCL) for As in drinking water from $50 \mu \mathrm{g} / \mathrm{L}$ to $10 \mu \mathrm{g} / \mathrm{L}$, effective on January 2006 in accordance with the WHO limit (US EPA, 2001). Leaching of As from natural or anthropogenic sources into groundwater is a major environmental concern. Anthropogenic activities such as metal smelting, coal combustion and application of As-containing compounds (herbicides, desiccants, and wood preservatives) have resulted in high local concentrations of As in soils.

Arsenic, a metalloid element, can have a variety of coordination numbers: 3, 4, 5 and 6 (Cullen and Reimer, 1989). The trivalent and pentavalent forms are the most common in soil environments. Arsenic (V) is less toxic than As(III) and also thermodynamically more stable under normal aerobic conditions (Smith et al., 1998).

Sorption of As on soil particles is an important process controlling its transport between various environmental compartments and has been studied by many researchers (Elkhatib et al., 1984a, Livesey and Huang, 1981, Sadiq et al., 1983, Bowell, 1994 and Belzile and Tessier, 1990). Studies have indicated that As shows irreversible sorption on soil particles and appears in close association with Al, Fe and Mn oxides (Jacobs et al., 1970, Sakata, 1987 and Elkhatib et al., 1984b). In order to characterize different pools of As with differential lability in soils, various methodological and instrumental approaches (SEM, EMPA and HPLC-ICP-MS) have been employed to identify As-bearing phases and As speciation (Matera et al., 2003). Besides these direct measurements, sequential chemical extraction is also a very useful procedure as an indirect measurement for As fractionation in soil and sediment. Wenzel et al. (2001) developed an improved sequential extraction procedure especially for As fractionation in soils. Based on the different extraction solution compositions used in this method, soil As associations can be classified into five fractions: (1) non-specifically sorbed; (2) specifically sorbed; (3) amorphous and poorly crystalline hydrous oxides of $\mathrm{Fe}$ and $\mathrm{Al}$; (4) well-crystallized hydrous oxides of $\mathrm{Fe}$ and Al; and (5) residual phases (Wenzel et al., 2001). Among these fractions, the affinity of As with those soil fractions generally increases from fraction 1 to fraction 5. Although sequential chemical extractions provide useful information about different As pools in the soil environment, the method does not give direct information about the kinetic leaching behavior of As from contaminated soils in the natural environment. Once in the soil environment, As is known to show a hysteretic desorption behavior from minerals and soils. In the study of Elkhatib et al. (1984b), only a small amount of the sorbed As(III) was released after five desorption steps. 
Fuller et al. (1993) indicated that only a small portion of As(V) desorbed from ferrihydrite after $144 \mathrm{~h}$ of reaction. In the study of O'Reiley et al. (2001), about $60 \%$ of arsenate remained bound to goethite even after 5 months of desorption by $6 \mathrm{mM}$ phosphate solution. Álvarez-Benedí et al. (2005) also found a strong hysteresis in the desorption process of As(V) from three Spanish agricultural soils. In order to make sound decisions and optimize the remediation efforts, it is necessary to have a thorough evaluation of the form, distribution and leachability of As in the contaminated soils.

This paper reports an experimental study of the form and distribution of As in two contaminated soils from active industrial sites in southeastern US using the simplified sequential extraction procedure developed by Wenzel et al. (2001), XRD analysis, and electron beam and synchrotron analytical techniques. In addition, sequential leaching experiments were also performed using the US EPA synthetic precipitation leaching procedure (SPLP) (US EPA, 1994a) and toxicity characteristic leaching procedure (TCLP) (US EPA, 1992) fluids to characterize and further evaluate the long term environmental leachability of As in the studied soils. The experimental results were used to provide further guidelines to facilitate the design of a cost-effective remediation method for the contaminated sites.

\section{Site description}

The two industrial sites, FW and $\mathrm{BH}$, in southeastern US were contaminated with As during the 1950s and 1960s due to the application of As containing herbicide to control weeds in the industrial facilities. The herbicide applied was As2O3 and had a trade name of Anaconda from the Anaconda smelter in Montana. Both sites are located near the Gulf Coast in the southeastern United States. Regional climate of the contaminated area is humid and semitropical with annual rainfall of about $162 \mathrm{~cm}$. Temperatures are moderate with an average high of $28{ }^{\circ} \mathrm{C}$ in summer and an average low of $10^{\circ} \mathrm{C}$ in winter. The background concentration of As in soils of the study areas is less than $3 \mathrm{mg} / \mathrm{kg}$. Soils in the study areas are sandy loams mainly derived from Quaternary undifferentiated terrace marine and fluvial sediment deposits. There are four major hydrogeologic units for the both sites: unconfined sand aquifer, a silty peat semi-confining bed, a semi-confined sand aquifer and a silt/clay confining unit. Site geology consists of an upper unsaturated unit, made up of white to yellowish gray, medium fine quartz sand approximately $1.52 \mathrm{~m}$ (5 feet) or less thick. Below this unit is saturated dark brown organic fine-grained quartz sand with some inter-fingering of coarse gravel. Immediately beneath the organic layer is a light brown to gray, medium to coarse-grained sand approximately $0.61-3.66 \mathrm{~m} \mathrm{(2-12} \mathrm{feet)} \mathrm{in}$ thickness. These three units comprise the surficial aquifer totalling a general thickness of $5.5 \mathrm{~m}$ (18 feet). The previous soil contamination assessment of the studied sites indicated that As contamination is mainly concentrated in the vadose zone topsoils of the upper unsaturated unit. (James C. Redwine, Southern Company Services, Inc., Pers. Commun., 2004). The contaminated areas are still active industrial sites located near heavily populated areas with many currently operating industrial facilities. Because As concentrations measured in some of the groundwater monitoring wells exceed the $10 \mu \mathrm{g} / \mathrm{L}$ regulatory standard, a thorough evaluation of the form, distribution and leachability of As in the contaminated soils is needed to aid the design of an effective remediation strategy to reduce the risk of As exposure to human populations. 


\section{Experimental}

\subsection{Sample collection and preparation}

Based on previous contamination assessments of the studied sites, contaminated soil samples were collected from each site at depths of 10-60 cm below the surface at selected locations to provide samples with high As concentrations. Two 19-L buckets of representative soil samples were collected from each site. The buckets were tightly sealed with lids and duct tape and immediately transported to the laboratory for analysis. A representative portion of each soil was put into an oven at $60{ }^{\circ} \mathrm{C}$ for moisture measurement. Oven-dried soil samples (at $60{ }^{\circ} \mathrm{C}$ ) were passed through $1 \mathrm{~mm}$ sieves to remove pebbles, then thoroughly mixing and used for microwave assisted acid digestion. Homogenized air-dried soils (passing $1 \mathrm{~mm}$ sieves) were used in sequential extractions, sequential leaching and all other subsequent analytical work.

\subsection{Bulk soil chemical analysis}

Soil $\mathrm{pH}$ and total organic C content (TOC) were determined by US EPA Methods 9045 and 415.1, respectively (US EPA, 1995 and US EPA, 1983). The As and trace element contents of each soil were determined by microwave-assisted acid digestion, according to US EPA Method 3051 (US EPA, 1994b). A representative $0.5 \mathrm{~g}$ soil sample was transferred into a Teflon microwave digestion vessel, followed by the addition of $10 \mathrm{~mL}$ concentrated reagent-grade HNO3 (ACS certified plus grade). The sample vessels were put into a Milestone MLS-1200 MEGA microwave digestion unit and heated for $10 \mathrm{~min}$. After digestion, the supernatant solutions were collected with a $10 \mathrm{~mL}$ plastic syringe and passed through $0.2 \mu \mathrm{m}$ nylon syringe filters. The filtered digestate solutions were stored in a refrigerator at $4{ }^{\circ} \mathrm{C}$ for later analysis by inductively coupled plasma-atomic emission spectroscopy (ICP-AES, Perkin-Elmer Optima 3500DV model). The soil digestions were performed in triplicate.

\subsection{Solid phase characterization}

Bulk soil mineralogy was determined by powder X-ray diffraction analysis using a Philips APD 3600 automated X-ray powder diffractometer (X-ray source: $\mathrm{Cu} \mathrm{K} \alpha$ radiation; Operating conditions: $45 \mathrm{kV}, 40 \mathrm{~mA}, 2-70^{\circ} 2 \theta$ ). Powder XRD analysis was also performed on $<2 \mu \mathrm{m}$ claysized particles separated by flotation according to Stock's law from both studied soils. A $150 \mathrm{~g}$ sample of contaminated soil was thoroughly dispersed in a $600 \mathrm{~mL}$ beaker by sonication in deionized water. After settling for $4 \mathrm{~h}$, a portion of the supernatant solution was vacuum filtered through a $0.45 \mu \mathrm{m}$ nylon membrane, the separated particles pressed onto a glass slide and allowed to dry.

Scanning electron microscopy (SEM) was performed using a Philips XL30 scanning electron microscope equipped with an energy dispersive spectrometer (EDS). Both bulk and clay-sized soil particles were $\mathrm{C}$ coated and analyzed by SEM to detect As-bearing phases. Semiquantitative chemical composition information for observed As-bearing particles was obtained by energy dispersive X-ray (EDX) spectroscopic analysis, followed by quantitative electron microprobe (EMP) analysis performed on a JEOL 8600 Superprobe equipped with EDS and five wavelength-dispersive spectrometers (WDS). The EMP was operated at $15 \mathrm{keV}$ with a $20 \mathrm{nA}$ specimen current and $0.5 \mu \mathrm{m}$ beam diameter.

Synchrotron micro-XRD and micron X-ray absorption near edge structure ( $\mu$-XANES) analysis of As-bearing particles were performed on beamline X26A at the National Synchrotron Light Source, Brookhaven National Laboratory. Selected As-bearing particles observed by SEM were 
mounted on glass slides using double-sided cellophane tape. All analyses were performed at room temperature in open air. For $\mu$-XRD analysis, samples were exposed to synchrotron X-ray radiation for $5 \mathrm{~min}$ at a beam energy of $13.2 \mathrm{keV}$ and the diffracted X-ray signal was collected with a Bruker SMART 1500 charge coupled device (CCD) detector. For $\mu$-XANES experiments, samples were scanned from $-50 \mathrm{eV}$ below the As $\mathrm{K}$ line absorption edge to $+100 \mathrm{eV}$ above the edge, using a scanning step of $0.05 \mathrm{eV}$ per second. The $\mu$-XANES analyses were performed in $\mathrm{X}$-ray fluorescence mode with a 9-element Ge array detector. Reagent grade $\mathrm{Na} 2 \mathrm{HAsO} 4 \cdot 7 \mathrm{H} 2 \mathrm{O}$, As2O5 and $\mathrm{Ca} 2(\mathrm{AsO} 4) 2$ were purchased from Sigma-Aldrich as the As standards for comparison of XANES spectra. Scorodite standard was provided by Dr. Antonio Lanzirotti of Brookhaven National Laboratory.

\subsection{Sequential chemical extractions}

Sequential chemical extraction procedures have been used routinely to determine the proportions of trace elements bonded to different phases in soils such as carbonates, Fe oxides and Al oxides. Representative $1 \mathrm{~g}$ samples of each soil were transferred into $50 \mathrm{~mL}$ conical polypropylene centrifuge tubes and subsequently extracted following the method developed by Wenzel et al. (2001). Because the focus of this study is on environmentally leachable As, the final $\mathrm{HNO} 3 / \mathrm{H} 2 \mathrm{O} 2$ microwave digestion step designed to attack the residual fraction of As was eliminated and the simplified 4-step sequential chemical extraction was used in this study. The extractions were performed in duplicate. The concentrations and volumes of the chemical reagents used, as well as the conditions and detailed procedures for each extraction step, are listed in Table 1. The extractant solutions were pushed through $0.2 \mu \mathrm{m}$ nylon syringe filters, acidified with Optima HNO3 to $\mathrm{pH}<2$, and refrigerated until analysis by ICP-AES.

Table 1.

Sequential chemical extraction procedure, adapted from Wenzel et al. (2001)

\begin{tabular}{|c|c|c|c|c|}
\hline Fraction & Extractant & Extraction conditions & $\mathrm{SSR}^{\mathrm{a}}$ & Wash step \\
\hline 1 & (NH4)2SO4 (0.05 M) & $4 \mathrm{~h}$ shaking, $20^{\circ} \mathrm{C}$ & $1: 25$ & \\
\hline$\frac{1}{2}$ & $(\mathrm{NH} 4) \mathrm{H} 2 \mathrm{PO} 4(0.05 \mathrm{M})$ & $16 \mathrm{~h}$ shaking, $20^{\circ} \mathrm{C}$ & $1: 25$ & \\
\hline$\frac{2}{3}$ & $\begin{array}{l}\text { NH4-oxalate buffer }(0.2 \mathrm{M}) ; \mathrm{pH} \\
3.25\end{array}$ & $4 \mathrm{~h}$ shaking in the dark, $20^{\circ} \mathrm{C}$ & $1: 25$ & $\begin{array}{l}\text { NH4-oxalate }(0.2 \mathrm{M}) ; \mathrm{pH} 3.25 \\
\text { SSR 1:12.5; } 10 \text { min shaking in the } \\
\text { dark }\end{array}$ \\
\hline 4 & $\begin{array}{l}\text { NH4-oxalate buffer }(0.2 \mathrm{M})+ \\
\text { ascorbic acid }(0.1 \mathrm{M}) ; \mathrm{pH} 3.25\end{array}$ & $\begin{array}{l}30 \text { min in a water basin at } 96^{\circ} \mathrm{C} \text { in } \\
\text { the light }\end{array}$ & $1: 25$ & $\begin{array}{l}\text { NH4-oxalate }(0.2 \mathrm{M}) ; \mathrm{pH} 3.25 \\
\text { SSR } 1: 12.5 ; 10 \text { min shaking in the } \\
\text { dark }\end{array}$ \\
\hline
\end{tabular}

a SSR: soil solution ratio

\subsection{Sequential TCLP and SPLP leaching}

Sequential leaching of the contaminated soils was performed using the extraction fluids described in US EPA Method 1311 (TCLP test) and Method 1312 (SPLP test). One gram of soil was transferred into a $20 \mathrm{~mL}$ glass vial, followed by the addition of $15 \mathrm{~mL}$ of either the SPLP or TCLP leachate fluid. The SPLP fluid was made by adding a dilute $60 / 40 \mathrm{wt} \%$ mixture of H2SO4 and HNO3 (ACS reagent grade) to ultrapure water (Milli-Q H2O purification system with resistivity of $18.2 \mathrm{M} \Omega \mathrm{cm}$ ) until the $\mathrm{pH}$ was $4.20 \pm 0.05$. The TCLP fluid was made by diluting $5.7 \mathrm{~mL}$ glacial acetic acid (ACS reagent grade) with ultrapure water to a volume of $1 \mathrm{~L}$ ( $\mathrm{pH}: 2.88$ $\pm 0.05)$. The $\mathrm{pH}$ of SPLP and TCLP fluids were checked before each use and monitored frequently. New leachate fluids were made if the fluid $\mathrm{pH}$ drifted beyond the specified values. The sample vials were put on a New Brunswick Innova 2100 horizontal orbital shaker for $11 \mathrm{~h}$ at $200 \mathrm{rpm}$. After leaching, the sample was centrifuged for $30 \mathrm{~min}$ at $3000 \mathrm{rpm}$, the supernatant solution was removed, another $15 \mathrm{~mL}$ of extraction fluid was added to the residue and the sample 
was subjected to another $11 \mathrm{~h}$ of leaching. The contaminated soil samples were leached with successive aliquots of fresh fluid until the As concentration in the supernatants approached the former regulatory limit for drinking water $(50 \mu \mathrm{g} / \mathrm{L})$. All extracted supernatant solutions were passed through $0.2 \mu \mathrm{m}$ nylon syringe filters, preserved by acidification and analyzed for total As by axial view ICP-AES. All sequential leaching experiments were performed in duplicate.

\section{Results and discussion}

\subsection{Bulk chemical analysis}

Both soil samples have circum-neutral $\mathrm{pH}$. The measured values are 7.5 for $\mathrm{BH}$ soil and 6.7 for FW soil. BH soil has a much higher total organic C content $(4200 \mathrm{mg} / \mathrm{kg})$ than FW soil (1900 $\mathrm{mg} / \mathrm{kg}$ ). Table 2 lists the As and major element compositions of the studied soils, as determined by microwave assisted acid digestion. Arsenic content in $\mathrm{BH}$ soil is much higher than that in FW soil. The mean concentration of $\mathrm{As}$ in $\mathrm{BH}$ and $\mathrm{FW}$ soil is $900 \mathrm{mg} / \mathrm{kg}$ and $325 \mathrm{mg} / \mathrm{kg}$, respectively. Both soils have comparable $\mathrm{Fe}, \mathrm{Mg}$ and $\mathrm{Al}$ contents, but $\mathrm{BH}$ has a much higher $\mathrm{Ca}$ content than FW. The Mn contents of the studied soils are $13 \mathrm{mg} / \mathrm{kg}(\mathrm{FW})$ and $100 \mathrm{mg} / \mathrm{kg}(\mathrm{BH})$, respectively, which are very low compared to the mean natural background level in US soils (330 mg/kg; Cooper, 1984). Although $\mathrm{Mn}$ is also a well-known scavenger for As, its low concentration would prevent $\mathrm{Mn}$ from playing any significant role in the retention of As in the studied soils. Therefore, Mn was not included in the suite of elements analyzed for this study.

Table 2.

Properties and selected metal contentsc of soils in the studied sites

\begin{tabular}{|c|c|c|}
\hline & FW & $\mathrm{BH}$ \\
\hline Total organic $\mathrm{Ca}(\mathrm{mg} / \mathrm{kg})$ & 1900 & 4200 \\
\hline Soil $\mathrm{pHb}$ & 6.7 & 7.5 \\
\hline Moisture (\%) & 4.3 & 7.6 \\
\hline $\mathrm{Al}(\mathrm{mg} / \mathrm{kg}$, dry weight) & $2558( \pm 82)$ & $2725( \pm 25)$ \\
\hline $\mathrm{Fe}(\mathrm{mg} / \mathrm{kg}$, dry weight) & $680( \pm 74)$ & $695( \pm 63)$ \\
\hline $\mathrm{Ca}(\mathrm{mg} / \mathrm{kg}$, dry weight $)$ & $617( \pm 56)$ & $1061( \pm 77)$ \\
\hline $\mathrm{Mg}(\mathrm{mg} / \mathrm{kg}$, dry weight $)$ & $183( \pm 65)$ & $210( \pm 39)$ \\
\hline $\mathrm{Mn}(\mathrm{mg} / \mathrm{kg}$, dry weight) & $13( \pm 4)$ & $100( \pm 11)$ \\
\hline \multicolumn{3}{|c|}{ a Determined according to EPA method 415.1 . } \\
\hline \multicolumn{3}{|c|}{ b Determined according to EPA method 9045 . } \\
\hline
\end{tabular}

\subsection{Powder XRD and SEM/EDX analysis}

Powder X-ray diffraction analysis of bulk samples and clay-sized particles showed quartz to be the dominant mineral phase in both of the studied soils. There were no other detectable crystalline phases in either soil, indicating that other soil minerals were either X-ray amorphous or present in quantities less than $1-5 \%$ by weight. SEM/EDX analysis indicated the presence of accessory mineral phases (e.g., rutile) in both of the soil samples. No As peaks were detected in EDX spectra of numerous FW soil particles examined, suggesting that As is disseminated throughout the soil. No individual phase that concentrates As was found by these methods in FW soil. 
Most of the As in BH bulk soil was observed as small As peaks in EDX spectra taken on the surfaces of some clay-sized particles (Fig. 1a). EDX analysis showed that besides Al, Si and O, which are common constituents of soil particles, the clay-sized particles also contained $\mathrm{Ca}, \mathrm{Fe}$ and As (Fig. 1b). There is no indication that As occurs as an individual As-rich phase on these clay-sized particles. Although BH samples were examined under SEM for several weeks, only one $100 \mu \mathrm{m}$ diameter particle found in bulk BH soil contained significantly higher As levels and looked to be an individual As-rich phase (Fig. 2a). EDX analysis showed that besides Al, Si, O, $\mathrm{Ca}, \mathrm{Fe}$ and As, this particle also contained S (Fig. 2b). Since most of the detected As was associated with clay-sized soil particles, the $<2 \mu \mathrm{m}$ fraction of $\mathrm{BH}$ soil was separated by flotation and also studied by SEM to further aid the detection of any As-bearing phases. Among numerous clay-sized particles examined, one was found to have unusually high As content, which showed sharp compositional contrast on the backscattered electron image and appeared to be an individual As-rich phase (Fig. 3). EDX analysis indicated that this particle consisted of Al, Si, O, $\mathrm{Ca}, \mathrm{Fe}$ and As. Although As-rich particles were detected in $\mathrm{BH}$ soil, the occurrence of those particles is very rare given the time spent under SEM and the total particles examined. EMP analysis was subsequently performed to obtain a quantitative chemical composition on the detected particles (see Section 4.3).

Fig. 1. (a) SEM photomicrograph and (b) EDX spectrum of an As-bearing particle in BH soil (AsL = As L line peak; all other elemental labels indicate K line peaks).

Fig. 2. (a) SEM photomiacrograph and (b) EDX spectrum of As-bearing particle in BH soil (AsL and FeL represent As and Fe L line peak; other elemental labels indicate their $K$ line peaks).

Fig. 3. (a) Secondary electron image (SEI) and (b) backscattered electron image (BEI) of the As-rich particle separated from the BH soil clay-sized fraction and used for EMP analysis (see Table 2).

\subsection{EMPA, $\mu-X R D$ and $\mu-X A N E S$ analysis of As-bearing particles}

Electron microprobe analysis was performed on the As-rich particles found in $\mathrm{BH}$ soil in an effort to obtain quantitative chemical compositions. It was found that the As-rich particle shown in Fig. 2 was not stable under the electron beam. The high temperature (several hundred ${ }^{\circ} \mathrm{C}$ ) produced by the electron beam burned spots on the particle surface, even after the current was greatly reduced, indicating that the phase was likely hydrated. Quantitative EMP analysis of this particle was abandoned. In contrast, the clay-sized As-rich particle shown in Fig. 3 was very stable under the electron beam and quantitative EMP analysis was successfully performed using wavelength-dispersive spectroscopy. Table 3 lists the EMP analysis data, which showed that the particle contained approximately $15 \%$ As by weight. However, the analysis obtained does not match the stoichiometry of any known As-bearing mineral. Except for a significantly higher As concentration, this particle had a chemical composition similar to other observed clay-sized Asbearing particles in $\mathrm{BH}$ soil, suggesting that this particle may be a mixture of an As phase and clay. 
Table 3.

Chemical composition of As-rich particle shown in Fig. 2, Fig. 3 and Fig. 4, as determined by EMPA

\begin{tabular}{|c|c|c|c|c|c|c|c|c|}
\hline Element & Elemental peak & k Value & k Ratio & El-Wt (\%) & MDLa & Norm-El (\%) & At-Propb & Error (\%) \\
\hline As & $\mathrm{L}$ & 0.0977 & 0.3499 & 15.52 & 0.1889 & 15.52 & 5.525 & 1.17 \\
\hline $\mathrm{Ca}$ & $\mathrm{K}$ & 0.0472 & 0.2864 & 4.86 & 0.0226 & 4.86 & 3.232 & 1.02 \\
\hline $\mathrm{Fe}$ & $\mathrm{K}$ & 0.2254 & 0.2254 & 24.94 & 0.0951 & 24.94 & 11.916 & 0.81 \\
\hline $\mathrm{Si}$ & $\mathrm{K}$ & 0.0662 & 0.1615 & 9.64 & 0.037 & 9.64 & 9.16 & 0.65 \\
\hline $\mathrm{Al}$ & $\mathrm{K}$ & 0.0439 & 0.1007 & 7.27 & 0.0334 & 7.27 & 7.183 & 0.91 \\
\hline \multirow[t]{3}{*}{$\mathrm{O}$} & Dc & 0.3777 & 0 & 37.77 & 0 & 37.77 & 62.985 & 0.00 \\
\hline & & & & & & & & \\
\hline & & & Total & 100 & & Total & 100 & \\
\hline
\end{tabular}

Synchrotron radiation-based $\mu$-XRD and $\mu$-XANES analytical techniques were also applied to identify the As-rich particles in BH soil. Because the clay-sized As-rich particle was too small for synchrotron radiation $\mu$-XRD and $\mu$-XANES analyses, the $100 \mu \mathrm{m}$ As-rich particle previously observed (Fig. 2) was hand-picked from BH soil under a petrographic microscope and re-examined by SEM/EDX to verify its identity. The $\mu$-XRD pattern collected for this particle was processed using FIT2D software developed by the European Synchrotron Radiation Facility (ESRF) (Hammersley, 1997 and Hammersley, 1998) to obtain d-space information. There were only two discernable peaks in the particle's diffraction pattern: one corresponding to a d-spacing of $1.80 \AA$ and the other corresponding to $2.08 \AA$, if only first order diffraction is assumed (Fig. 4). However, after comparison with available data for known As-bearing minerals, none was found to exactly match the chemical composition and XRD pattern of this particle. Based on the chemical composition of the studied particle, higher order diffraction peak matches were also tried to determine possible minerals. It was found that a $3 \mathrm{rd}$ order diffraction peak corresponding to the observed $2.08 \AA$ peak $(6.23 \AA$ ) gives a very good match with the 100 -intensity peak of phaunouxite [Ca3(AsO4) $\cdot 11 \mathrm{H} 2 \mathrm{O}]$, and a $3 \mathrm{rd}$ order peak corresponding to the observed $1.8 \AA$ peak $(5.4 \AA)$ matches the 100 -intensity peak of vyalsovite $[\mathrm{FeS} \cdot \mathrm{Ca}(\mathrm{OH}) 2 \cdot \mathrm{Al}(\mathrm{OH}) 3]$. Although these minerals also have other diffraction peaks that did not appear in the $\mu$-XRD pattern of this As-rich particle, it is possible that higher background noise caused by mounting the particle on a glass slide concealed the lower intensity diffraction peaks. It is probable that this As-rich particle consists of a mixture of two or more phases.

Fig. 4. The derived d-spacings of the As-rich particle hand picked from BH soil shown in Fig. 2 (assuming 1st order diffraction).

XANES analysis is very sensitive to the chemical valence state of an element and its coordination environment within the mineral structure (Koningsberger and Prins, 1988). XANES analysis may therefore be used as a 'fingerprint' to detect the presence of a particular element and determine its valence and speciation by comparison with the spectra of its standard compounds (Huffman et al., 1994, Huggins et al., 2000a and Huggins et al., 2000b). A $\mu-$ XANES spectrum was collected on the As-rich particle and compared with those of standard As compounds (Fig. 5). It was shown that the X-ray absorption near-edge structure of the particle is 
very similar to calcium arsenate, which is consistent with the tentative higher order X-ray diffraction identification of phaunouxite. Weathering has therefore oxidized and converted the As $2 \mathrm{O} 3$ in these soils to the +5 valence of arsenate.

Fig. 5. Comparison of X-ray absorption near-edge structure (XANES) of the As-rich particle hand-picked from BH soil and standard As-containing compounds.

According to historical data for the study sites, herbicide containing As2O3 is the only source of As contamination to $\mathrm{FW}$ and $\mathrm{BH}$ soils. One possible explanation for the occurrence of the Asrich particles in $\mathrm{BH}$ soil is their formation from As2O3 in the weathering environment. The tentative identification of phaunouxite, the association of $\mathrm{Ca}$ and As in the EDX spectra of Asbearing particles, and the high As and $\mathrm{Ca}$ contents of $\mathrm{BH}$ soil seem to suggest that $\mathrm{Ca}$ helps retain and further stabilize soil As into more crystalline forms, possibly as calcium arsenate, in a weathering environment. However, the scarcity of the detected crystalline As-rich phase suggests that the majority of soil As is not present as crystalline As-rich phases. Verification of the identity of secondary As-bearing phases and the exact processes of their formation need further study.

\subsection{Sequential chemical extractions}

The fractions of As extracted by each step in the modified sequential chemical extraction procedure are: (1) non-specifically sorbed As (S1), (2) specifically sorbed As (S2), (3) As associated with amorphous and poorly crystalline hydrous oxides of Fe and Al (S3), and (4) As associated with well-crystallized hydrous oxides of Fe and Al (S4). The extraction results are shown in Table 4. Percentage of total extractable As, Al and Fe is also calculated using amounts extracted in each SCEP step divided by the sum of the total amount extracted by all SCEP steps and the results are shown in Fig. 6.

Table 4.

$\mathrm{As}, \mathrm{Al}$ and Fe removed (mg/kg) in each sequential chemical extraction step

\begin{tabular}{|l|l|l|l|l|l|l|}
\hline Soil fraction & $\mathrm{As}(\mathrm{mg} / \mathrm{kg})$ & $\mathrm{Al}(\mathrm{mg} / \mathrm{kg})$ & $\mathrm{Fe}(\mathrm{mg} / \mathrm{kg})$ & & \\
\hline & $\mathrm{BH}$ & $\mathrm{FW}$ & $\mathrm{BH}$ & $\mathrm{FW}$ & $\mathrm{BH}$ \\
\hline S1 & $98.49( \pm 2.23)$ & $40.37( \pm 0.69)$ & $3.37( \pm 0.24)$ & $4.24( \pm 0.40)$ & $0.08( \pm 0.04)$ \\
\hline S2 & $250.96( \pm 8.44)$ & $99.94( \pm 1.83)$ & $14.61( \pm 0.01)$ & $22.02( \pm 0.55)$ & $0.47( \pm 0.02)$ \\
\hline S3 & $346.96( \pm 5.73)$ & $93.54( \pm 6.05)$ & $714.02( \pm 21.83)$ & $322.7( \pm 20.26)$ & $0.22( \pm 0.03)$ \\
\hline S4 & $17.26( \pm 0.63)$ & $17.97( \pm 0.27)$ & $204.32( \pm 3.41)$ & $326.16( \pm 7.81)$ & $0.79( \pm 0.02)$ \\
\hline
\end{tabular}

Note: The numbers in bracket represent $1 \sigma$ standard deviation.

Fig. 6. (a) As, (b) Al and (c) Fe distributions in FW and BH soils as determined by the 4step sequential chemical extraction procedure modified from Wenzel et al. (2001).

The sequential chemical extraction results show that the majority of soil As was extracted by the 2nd and 3rd extraction steps for both studied soils. For FW soil, As was distributed evenly between the 2 nd and 3 rd fractions (39.69\% and 37.15\%, respectively), with the smallest amount 
of As extracted in the 4th step (7.14\%). While for BH soil, the largest portion of soil As was extracted by the 3 rd step (48.6\%), then the 2 nd step (35.2\%), and the smallest fraction of As was extracted by the 4 th step $(2.4 \%)$.

Comparing the distributions of As, $\mathrm{Al}$ and Fe for FW and $\mathrm{BH}$ soils in Fig. 6, it is apparent that the percentages of amorphous or poorly crystalline $\mathrm{Al}$ and Fe hydrous oxides extracted by the 3rd SCEP step from BH soil are greater than those removed from FW soil, while the percentages of the crystalline $\mathrm{Al}$ and Fe hydroxides extracted by the 4th SCEP step from FW soil are greater than for $\mathrm{BH}$ soil. Compared to FW soil, higher percentages of As, Al and Fe were extracted in the 3rd SCEP step for BH soil, indicating that the higher level of As in BH soil is primarily associated with amorphous $\mathrm{Al}$ and Fe hydrous oxides. Although crystalline As-rich phases were observed in BH soil, a significant amount of the total As was extracted by the first two SCEP steps (13.8\% and 35.2\%, respectively), which are designed to extract the most labile portion of soil As. These results indicate that approximately half of $\mathrm{BH}$ soil As is not confined to crystalline As-bearing phases.

\subsection{Sequential TCLP and SPLP leaching}

BH and FW soils were sequentially leached by SPLP fluid for over 600 and $200 \mathrm{~h}$, respectively, before the As concentration in the supernatant solutions fell below the former drinking water standard MCL $(50 \mu \mathrm{g} / \mathrm{L})$. For TCLP leaching, both soils were sequentially leached for over $600 \mathrm{~h}$ before the supernatant As concentration fell below the As drinking water MCL. Because the soils have different As contents, the percentages of total As that were cumulatively leached by SPLP and TCLP sequential leaching were calculated based on the total soil As contents determined by EPA method 3051 to better compare the As leaching behavior of the soils. The results are shown in Fig. 7. Supernatant solution As concentration against time curves for SPLP and TCLP leaching are shown in Fig. 8. In order to show differences in As leaching behavior at low concentration levels, leachate As concentrations are plotted on a log scale in Fig. 8.

\section{Fig. 7. (a) SPLP leaching behavior and (b) TCLP leaching behavior of As from BH and FW soils.}

Fig. 8. Comparison of As leaching behavior for $\mathrm{BH}$ and $\mathrm{FW}$ soils during (a) TCLP and (b) SPLP sequential leaching (As concentration is plotted on a log scale).

Both studied soils showed an initial rapid release of As, followed by a gradual approach to an asymptote for TCLP leaching (Fig. 7). A higher percentage of the total As was leached by the TCLP fluid from FW soil $(82 \%)$ than from BH soil $(73 \%)$. For SPLP leaching, comparable percentages of total As were leached by SPLP fluid in both studied soils (27\% versus $24 \%$ for $\mathrm{FW}$ and $\mathrm{BH}$, respectively), the $\mathrm{BH}$ sample showed a slower release of As compared to the $\mathrm{FW}$ soil sample. The total SPLP leaching time period for BH soil spanned more than $600 \mathrm{~h}$ while it only lasted about $200 \mathrm{~h}$ for FW soil before the supernatant solution As concentration dropped below the $50 \mu \mathrm{g} / \mathrm{L}$ limit. More significantly, a much lower percentage of the total As was leached from $\mathrm{BH}$ soil during the first $200 \mathrm{~h}$ of SPLP sequential leaching. These observations suggest that $\mathrm{BH}$ soil has a greater ability to retain As than FW soil. 
For both soil samples, the TCLP fluid leached a higher percentage of the total As than the SPLP fluid. In contrast, SPLP leaching removed less than $30 \%$ of the total microwave-acid digestible As (determined by EPA method 3051) in both of the studied samples. This observation is consistent with the compositional differences between the two leachate solutions; the SPLP fluid is made of a dilute mixture of $\mathrm{H} 2 \mathrm{SO} 4$ and $\mathrm{HNO} 3$ and has a $\mathrm{pH}$ of 4.20, while the TCLP fluid is an acetic acid solution with a $\mathrm{pH}$ of 2.88 . Because the TCLP solution is a much more aggressive leachate, the As removed from the soils by TCLP sequential leaching essentially represents the maximum level of environmental leachable As. By similar reasoning, the SPLP fluid should be more appropriate for simulating As leaching from soils in the natural environment. Therefore, the information provided by SPLP sequential leaching will be used to evaluate the long-term leaching behavior of As from the studied soil samples. The results given above indicate that As would be significantly less mobile under natural leaching conditions than shown by TCLP sequential leaching.

Fig. 8 shows that BH and FW soils share similar As leaching behavior for TCLP and SPLP sequential leaching. The leachate As concentration against time curves for TCLP leaching can be divided into three regions, based on the slope changes occurring at $109 \mathrm{~h}$ and at $193 \mathrm{~h}$ (Fig. 8a). The As leaching curves before $193 \mathrm{~h}$ show steeper slopes (more rapid As leaching behavior), while the curves after $193 \mathrm{~h}$ have much lower slopes (slower As leaching behavior) in both of the studied soils. The observed differences in As leaching behavior before and after $193 \mathrm{~h}$ suggest that different sources of As were mobilized during the leaching process. Another similar feature between the TCLP leaching curves for the studied soils is the presence of As 'terraces', which occur concurrently at $109 \mathrm{~h}$ and could be attributable to dissolution of phases associated with As. Along with As, both soils showed simultaneous release of Al, Fe and Si at 109 h (Fig. 9), which suggests that the dissolving phase that incorporates As also contains $\mathrm{Al}, \mathrm{Fe}$ and $\mathrm{Si}$. Arsenic 'terraces' at $109 \mathrm{~h}$ were also present in the SPLP sequential leaching curves of the studied soils (Fig. 8b). Examining other element concentration versus time curves for SPLP leaching (Fig. 10), it can be seen that Si was released concurrently with As at $109 \mathrm{~h}$ from both studied soils. The above results indicate that a portion of the As may be hosted by a silica-rich phase. Given the comparatively less aggressive nature of SPLP fluids, quartz, which is the major mineral component of the studied soils, is unlikely to be the Si source. Instead, dissolution of amorphous silica derived from weathering of quartz is a more likely cause of the observed As 'terraces' at $109 \mathrm{~h}$ in the SPLP leaching curves.

Fig. 9. Comparison of element leaching behavior during TCLP sequential leaching for (a) FW and (b) BH soils (the vertical axis was in log scale).

Fig. 10. Comparison of element leaching behavior during SPLP sequential leaching for (a) FW and (b) BH soils (note the log scale on the vertical axis).

Compared to SPLP leaching of FW soil, the SPLP leaching curves for BH soil show an additional feature: small rises in leachate As and Si concentrations after $193 \mathrm{~h}$ (Fig. 10b). Compared with the SPLP leaching curves of other elements, the leaching pattern of Si correlates very well with that of As beginning at about $109 \mathrm{~h}$. This further supports the idea that some of 
the soil As is closely associated with a silica phase or phases. Below, the SCEP results are compared to those of SPLP/TCLP sequential leaching to better interpret the mobility of As associated with different soil fractions.

\subsection{Comparison of the results of SCEP and sequential SPLP/TCLP leaching}

In order to better evaluate the environmental leaching behavior of As associated with different soil fractions, the sequential SPLP/TCLP leaching and the sequential chemical extraction procedure (SCEP) results were compared. Fig. 11 compares the total As leached by SPLP and TCLP fluids (until supernatant solution As concentrations reached the drinking water MCL at the time of the study) with the As extracted by all of the sequential chemical extraction steps, combined. Although the sum of As extracted by the SCEP was less than the total As removed by TCLP leaching from FW soil, the totals were similar for BH soil. Considering the error caused by the incomplete withdrawal of fluid during each consecutive sequential leaching step, the results for each soil are remarkably similar. Therefore, the total As extracted from the studied soils by the SCEP is comparable to that leached by the TCLP fluid and thus appears to adequately represent the maximum level of environmentally leachable As. Arsenic removed by the SCEP will be termed "total extractable As" in the following discussion. Fig. 11 also shows that SPLP leaching removed only about $30 \%$ of the total As extracted by the SCEP, indicating that significant portions of As associated with certain soil fractions in the studied soils are relatively stable and resistant to natural leaching.

Fig. 11. Comparison of As mobilized by SPLP and TCLP sequential leaching with total extractable As, as determined by SCEP.

In the SCEP, extraction steps 1 and 2 are designed to remove the most labile portion of soil As. Compared to the total SPLP-leachable As, it appears that a significant portion of the As extracted in the first two SCEP steps is fairly resistant to acid rainwater leaching (Fig. 12). Both of the soils were leached by SPLP fluid until As in the supernatant solution reached $50 \mu \mathrm{g} / \mathrm{L}$. However, only $34 \%$ and $30 \%$ of the total extractable As was removed by sequential SPLP leaching, while $56 \%$ and $49 \%$ of the total extractable As was removed in the first two SCEP steps from FW and BH soils, respectively. In other words, $22 \%$ and $19 \%$ of the As extracted by the first two SCEP steps was essentially unleachable by SPLP fluid from FW and BH soils, respectively (Fig. 12).

Fig. 12. Comparison of the results of SPLP sequential leaching with the total removed by the first two SCEP steps for (a) FW and (b) BH soil.

Similar comparisons are also made in Fig. 12 of the percentages of total extractable Al and Fe removed from each soil by SPLP sequential leaching and by SCEP extraction steps 1 and 2. The percentages of total extractable Al and Fe removed from the soils by SPLP leaching are slightly higher than the amounts of these elements removed by the first two SCEP steps. However, the differences are small when compared to the percentages of $\mathrm{Al}$ and $\mathrm{Fe}$ extracted by the third SCEP step in both of the studied soils, indicating that very little of the amorphous Al and Fe was mobilized by SPLP sequential leaching (Fig. 13). Although As associated with amorphous Al 
and $\mathrm{Fe}$ is still of environmental concern and is the focus of many studies, these results suggest that the portion of soil As associated with amorphous Al and Fe oxyhydroxides is fairly stable against environmental leaching under aerobic conditions.

Fig. 13. Comparison of Al and Fe mobilized by the third SCEP step and the differences between SPLP sequential leaching and the first two SCEP steps for FW and BH soil.

It is also useful to compare the SCEP total extractable As with the features observed previously in the SPLP leachate As concentration against time curves. The first SCEP step is designed to extract the non-specifically absorbed and thus most labile portion of soil As, which would be readily soluble upon leaching. Fig. 14 compares the percentages of total extractable As removed by initial SPLP leaching and by the first SCEP step. The quantities are comparable in FW soils, with $12.46 \%$ removed by initial SPLP leaching and $16 \%$ by the first SCEP step. However, for the BH soil, the first SCEP step extracted a significantly higher portion of the total As than that removed by initial SPLP leaching, suggesting stronger affinity of As in BH soils against acid rainwater leaching.

Fig. 14. Comparison of the percentage of total extractable As mobilized initially, after $109 \mathrm{~h}$ of leaching, and by total SPLP sequential leaching, and by the first SCEP step for $\mathrm{FW}$ and $\mathrm{BH}$ soil.

The percentages of total extractable As removed by $109 \mathrm{~h}$ of SPLP leaching were also calculated and are shown in Fig. 14. After $109 \mathrm{~h}$ of sequential leaching, BH soil showed comparable amounts of As removed by SPLP leaching and by the first SCEP step, while nearly all SPLPleachable As was removed by 109 h of SPLP leaching from FW soil. The observed As 'terraces' at $109 \mathrm{~h}$ therefore seem to delineate certain As pools in the studied samples. For FW soil, it represents the total As that is available for natural acid rain leaching; while, for $\mathrm{BH}$ soil, it indicates the most easily mobilized fraction of soil As.

Although SCEP indicates portions of As associated with soil fractions extracted by the first and second SCEP steps are comparable in both studied soils, the above comparisons clearly show that $\mathrm{BH}$ soil has a much slower As release behavior compared to FW samples. Compared to the FW soil, the BH sample has significantly higher percentage of amorphous Al, Fe oxyhydroxides, which are well known scavengers for As in the soil environment. EXAFS studies indicate As, especially As(V), can form a suite of inner-sphere surface complexes with Al and Fe hydroxides (Waychunas et al., 1993, Fendorf et al., 1997 and Arai et al., 2001). In upper surface zone well aerobic environment, $\mathrm{As}(\mathrm{V})$ is likely to be the dominant form in the contaminated sites. The slow leaching behavior of As from BH soil is explained by the strong affinity of As with amorphous Al, Fe oxyhydroxides.

Fig. 15 compares the percentages of As, Al and Fe removed by $193 \mathrm{~h}$ of TCLP leaching and by the first three SCEP steps. Nearly all of the extractable As and the amorphous or poorly crystalline Al were removed by $193 \mathrm{~h}$ of TCLP leaching from both soil samples. However, only a small portion of the total Fe was removed by TCLP leaching, compared to the amount present 
as amorphous Fe oxyhydroxides. It appears that soil As is more closely associated with amorphous Al oxyhydroxides than with amorphous Fe oxyhydroxides for the studied soils. Therefore, the change in slope of the TCLP leaching curves at $193 \mathrm{~h}$ likely indicates consumption of As pools associated with amorphous Al and silica fractions.

\section{Fig. 15. Comparison of the percentages of total extractable metal concentrations removed by $193 \mathrm{~h}$ of TCLP sequential leaching and by the first three SCEP steps for (a) FW and (b) BH soils.}

\section{Conclusions}

SEM/EDX analyses and sequential chemical extraction experiments show that most of the extractable As in both FW and $\mathrm{BH}$ soils is present as sorbed species on the surfaces of soil particles and associated with amorphous $\mathrm{Al}$ and $\mathrm{Fe}$ oxyhydroxides. Although an As-rich phase was detected in $\mathrm{BH}$ soil and tentatively identified as phaunouxite [Ca3(AsO4)2 $111 \mathrm{H} 2 \mathrm{O}]$, the occurrence of these particles is so rare that they cannot account for the majority of As present in $\mathrm{BH}$ soil. This is supported by the failure of bulk powder XRD analysis to detect any As-bearing phases and by the sequential chemical extraction results which indicate that a significant portion of the total extractable As is present in the labile BH soil fractions.

The sequential chemical extraction experiments also showed that more As is bound to amorphous $\mathrm{Al}$ and $\mathrm{Fe}$ oxyhydroxides in the $\mathrm{BH}$ soil compared to the FW sample. Although microwave-assisted acid digestion showed comparable $\mathrm{Al}$ and Fe contents for these soils, the percentages of amorphous $\mathrm{Al}$ and Fe oxyhydroxides in $\mathrm{BH}$ soil were much higher than those in FW soil. Such differences in As distribution would account for the observed differences in As mobility between the studied soils. SPLP sequential leaching and SCEP experiments also indicate that significant portions of As associated with soil fractions extracted by the 2nd SCEP step are resistant to acid rainwater leaching. Since As contamination is mainly concentrated in the upper surface zone well aerobic environment, $\mathrm{As}(\mathrm{V})$ is likely to be the dominant form in the contaminated sites. The observed leaching behavior is explained by the fact that As is present in these soils in the +5 valence state and primarily held on amorphous $\mathrm{Al}$, Fe oxyhydroxide surfaces possibly as bidentate surface complexes.

The major environmental concern for the study sites is the potential leaching of As into groundwater. The SPLP sequential leaching experiments do indicate that a portion of the total extractable As in the studied soils is mobile during natural leaching. Once mobilized and leached into groundwater, the As plume can potentially be transported offsite and cause the contamination of nearby drinking water supplies. Mobilization of As from the studied soils, especially its leaching into groundwater, may therefore pose a threat to the health of residents of the surrounding communities.

Excavation of the contaminated soils would be the first choice for the remediation of contaminated sites. However, this practice is difficult-to-impossible to perform since the contaminated sites are very large and the majory of them are still active industrial sites with very limited access to heavy equipment. The SPLP leaching experiments conducted for this study indicated that As is released very slowly from the studied soils. Even for FW soil, which showed quicker As release, it took more than $200 \mathrm{~h}$ of sequential leaching in a well agitated laboratory 
environment to remove all SPLP-leachable As. The SPLP leaching experiments also suggest that only a small portion of As in these soils is leachable under surficial normal weathering conditions. Considering the circumstances of the studied sites, remediation efforts can be directed towards reducing As mobility by chemically modifying soil properties to facilitate the formation of more stable As-bearing compounds at contaminated sites.

\section{Acknowledgements}

The authors thank Dr. Michael G. Bersch and Betsy Graham in the University of Alabama for their assistance in electron microprobe and ICP-AES analyses of the studied samples. We thank Dr. Antonio Lanzirotti at National Synchrotron Light Source of Brookhaven National Laboratory for his help with data collection on Beamline X26A. This work was funded by Southern Company and Electric Power Research Institute.

\section{References}

Álvarez-Benedí et al., 2005 J. Álvarez-Benedí, S. Bolado, I. Cancillo, C. Calvo and D. GarcíaSinovas, Adsorption-desorption of arsenate in three Spanish soils, Vadose Zone J. 4 (2005), pp. 282-290.

Arai et al., 2001 Y. Arai, E.J. Elzinga and D.L. Sparks, X-ray absorption spectroscopic investigation of arsenite and arsenate adsorption at the aluminum oxide-water interface, J. Colloid Interface Sci. 235 (2001), pp. 80-88.

ATSDR, 2000 ATSDR, 2000. Toxicological Profile for Arsenic. US Department of Health and Human Services, Public Health Service, Agency for Toxic Substances and Disease Registry, Atlanta, GA.

Backer and Chesnin, 1975 D.E. Backer and L. Chesnin, Chemical monitoring of soils for environment quality and animal and human health, Adv. Agron. 27 (1975), pp. 305-374.

Belzile and Tessier, $1990 \mathrm{~N}$. Belzile and A. Tessier, Interactions between arsenic and iron oxyhydroxides in lacustrine sediments, Geochim. Cosmochim. Acta 54 (1990), pp. 103109.

Bowell, 1994 R.J. Bowell, Sorption of arsenic by iron oxides and hydroxides in soils, Appl. Geochem. 9 (1994), pp. 279-286.

Colbourn et al., 1975 P. Colbourn, B.J. Alloway and I. Thornton, Arsenic and heavy metals in soils associated with regional geochemical anomalies in south-west England, Sci. Total Environ. 4 (1975), pp. 359-363.

Cooper, 1984 W.C. Cooper, The health implications of increased manganese in the environment resulting from the combustion of fuel additives: a review of the literature, J. Toxicol. Environ. Health 14 (1984), pp. 23-46.

Cullen and Reimer, 1989 W.R. Cullen and K.J. Reimer, Arsenic speciation in the environment, Chem. Rev. 89 (1989), pp. 713-764.

Dragun and Chiasson, 1991 J. Dragun and A. Chiasson, Elements in North American Soils, Hazardous Materials Control Resources Institute, Greenbelt, MD (1991). 
Elkhatib et al., 1984a E.A. Elkhatib, O.L. Bennett and R.J. Wright, Kinetics of arsenite sorption in soils, Soil Sci. Soc. Am. J. 48 (1984), pp. 758-762.

Elkhatib et al., 1984b E.A. Elkhatib, O.L. Bennett and R.J. Wright, Arsenite sorption and desorption in soils, Soil Sci. Soc. Am. J. 48 (1984), pp. 1025-1030.

Fendorf et al., 1997 S. Fendorf, M.J. Eick, P. Grossle and D.L. Sparks, Arsenate and chromate retention mechanisms on goethite. 1. Surface structure, Environ. Sci. Technol. 31 (1997), pp. 315-320.

Fuller et al., 1993 D.C. Fuller, J.A. Davis and G.A. Waychuna, Surface chemistry of ferrihydrite. Part 2. Kinetics of arsenate adsorption and coprecipitation, Geochim. Cosmochim. Acta 57 (1993), pp. 2271-2282.

Hammersley, 1997 Hammersley, A.P., 1997. FIT2D: an introduction and overview. ESRF internal report: ESRF97HA02T.

Hammersley, 1998 Hammersley, A.P., 1998. FIT2D V10.3 reference manual V4.0. ESRF internal report: ESRF98HA01T.

Huffman et al., 1994 G.P. Huffman, F.E. Huggins, N. Shah and J. Zhao, Speciation of arsenic and chromium in coal and combustion ash by XAFS spectroscopy, Fuel Proc. Technol. 39 (1994), pp. 47-62.

Huggins et al., 2000a F.E. Huggins, G.P. Huffman and J.D. Robertson, Speciation of elements in NIST particulate matter SRMs 1648 and 1650, J. Hazard. Mater. 74 (2000), pp. 1-23.

Huggins et al., 2000b F.E. Huggins, N. Shah, G.P. Huffman and J.D. Robertson, XAFS spectroscopic characterization of elements in combustion ash and fine particulate matter, Fuel Proc. Technol. 66 (2000), pp. 203-218.

Hutton, 1987 M. Hutton, Human health concerns of lead, mercury, cadium and arsenic. In: T.C. Hutchinson and K.M. Meema, Editors, Lead, Mercury, Cadium and Arsenic in the Environment, Wiley, New York (1987), pp. 53-68 (Chapter 6).

Jacobs et al., 1970 L.W. Jacobs, J.K. Myers and D.R. Keeny, Arsenic sorption by soils, Soil Sci. Am. Proc. 34 (1970), pp. 750-754.

Koningsberger and Prins, 1988 D.C. Koningsberger and R. Prins, X-ray Absorption: Principles, Applications, Techniques of EXAFS, SEXAFS and XANES, Wiley, New York (1988).

Livesey and Huang, 1981 N.T. Livesey and P.M. Huang, Adsorption of arsenate on soils and its relation to selected chemical properties and anions, Soil Sci. 13 (1981), pp. 88-94.

Matera et al., 2003 V. Matera, I.L. Hecho, A. Laboudigue, P. Thomas, S. Tellier and M. Astruc, A methodological approach for the identification of arsenic bearing phases in polluted soils, Envrion. Pollut. 126 (2003), pp. 51-64.

National Research Council, 1977 National Research Council, Arsenic, National Academy of Sciences, Washington, DC (1977).

O’Reiley et al., 2001 S.E. O'Reiley, D.G. Strawn and D.L. Sparks, Residence time effects on arsenate adsorption/desorption mechanisms on goethite, Soil Sci. Soc. Am. J. 65 (2001), pp. 67-77. 
Sadiq et al., 1983 M. Sadiq, T.H. Zaidi and A.A. Mian, Environmental behavior of arsenic in soils: theoretical, Water, Air, Soil Pollut. 20 (1983), pp. 369-377.

Sakata, 1987 M. Sakata, Relationship between adsorption of arsenic (III) and boron by soil and soil properties, Environ. Sci. Technol. 21 (1987), pp. 1126-1130.

Shacklette and Boerngen, 1984 Shacklette, H.T., Boerngen, J.G., 1984. Element Concentrations in Soils and Other Surficial Materials of the Conterminous United States. US Geol. Surv. Prof. Paper 1270.

Smith et al., 1998 E. Smith, R. Naidu and A.M. Alston, Arsenic in the soil environment: a review, Adv. Agron. 64 (1998), pp. 149-195.

US EPA, 1983 US EPA, 1983. Method 415.1: Organic carbon, total-combustion or oxidation. In: Methods for Chemical Analysis of Water and Wastes, EPA/600/4-79/020. US Environmental Protection Agency, Office of Research and Development, Cincinniti.

US EPA, 1992 US EPA, 1992. Method 1311: Toxicity characteristic leaching procedure. In: Test Methods for Evaluating Solid Waste, Physical/Chemical methods, third ed., US Environmental Protection Agency, Office of Solid Waste. US Government Printing Office: Washington, DC.

US EPA, 1994a US EPA, 1994a. Method 1312: Synthetic precipitation leaching procedure. In: Test Methods for Evaluating Solid Waste, Physical/Chemical methods, third ed., US Environmental Protection Agency, Office of Solid Waste. US Government Printing Office: Washington, DC.

US EPA, 1994b US EPA, 1994b. Method 3051: Micro-wave assisted acid digestion of sediments, sludges, soils and oils. In: Test Methods for Evaluating Solid Waste, Physical/Chemical methods, third ed., US Environmental Protection Agency, Office of Solid Waste. US Government Printing Office: Washington, DC.

US EPA, 1995 US EPA, 1995. Method 9045C: Soil and waste pH. In: Test Methods for Evaluating Solid Waste, Physical/Chemical methods, third ed., US Environmental Protection Agency, Office of Solid Waste. US Government Printing Office: Washington, DC.

US EPA, 2001 US EPA, 2001. Available from: <http://www.epa.gov/safewater/mcl.html\#mcls>.

Waychunas et al., 1993 G.A. Waychunas, B.A. Rea, C.C. Fuller and J.A. Davis, Surface chemistry of ferrihydrite. Part 1. EXAFS studies of the geometry of co-precipitated and adsorbed arsenate, Geochim. Cosmochim. Acta 57 (1993), pp. 2251-2269.

Wenzel et al., 2001 W.W. Wenzel, N. Kirchbaumer, T. Prohaska, G. Stingeder, E. Lombi and D.C. Adriano, Arsenic fractionation in soils using an improved sequential extraction procedure, Anal. Chim. Acta 436 (2001), pp. 309-323. 